\title{
Climate dependent contrast in surface mass balance in East Antarctica over the past 216 ka
}

\author{
F. PARRENIN, ${ }^{1,2} *$ S. FUJITA, ${ }^{3,4} *$ A. ABE-OUCHI ${ }^{5,6}$ K. KAWAMURA, ${ }^{3,4}$ \\ V. MASSON-DELMOTTE, ${ }^{7}$ H. MOTOYAMA,${ }^{3,4}$ F. SAITO,${ }^{6}$ M. SEVERI, ${ }^{8}$ B. STENNI, ${ }^{9}$ \\ R. UEMURA, ${ }^{10}$ E. W. WOLFF ${ }^{11}$ \\ ${ }^{1}$ CNRS, LGGE, F-38041 Grenoble, France \\ ${ }^{2}$ University Grenoble Alpes, LGGE, F-38041 Grenoble, France \\ ${ }^{3}$ National Institute of Polar Research, Research Organization of Information and Systems, Tokyo, Japan \\ ${ }^{4}$ Department of Polar Science, The Graduate University for Advanced Studies (SOKENDAI), Tokyo, Japan \\ ${ }^{5}$ Atmosphere and Ocean Research Institute (AORI), University of Tokyo, Chiba, Japan \\ ${ }^{6}$ Japan Agency for Marine-Earth Science and Technology, Yokohama, Japan \\ ${ }^{7}$ Laboratoire des Sciences du Climat et de l'Environnement, Institut Pierre Simon Laplace, UMR CEA-CNRS-UVSQ-UPS \\ 8212, Gif-sur-Yvette, France \\ ${ }^{8}$ Department of Chemistry, University of Florence, Florence, Italy \\ ${ }^{9}$ Department of Environmental Sciences, Informatics and Statistics, Ca' Foscari University Venice, 30123 Venice, Italy \\ ${ }^{10}$ Department Chemistry, Biology and Marine Science, Faculty of Science, University of the Ryukyus, Okinawa, Japan \\ ${ }^{11}$ Department of Earth Sciences, University of Cambridge, Cambridge, UK \\ Correspondence: Frédéric Parrenin <parrenin@ujf-grenoble.fr> and Shuji Fujita <sfujita@nipr.ac.jp>
}

\begin{abstract}
Documenting past changes in the East Antarctic surface mass balance is important to improve ice core chronologies and to constrain the ice-sheet contribution to global mean sea-level change. Here we reconstruct past changes in the ratio of surface mass balance (SMB ratio) between the EPICA Dome C (EDC) and Dome Fuji (DF) East Antarctica ice core sites, based on a precise volcanic synchronization of the two ice cores and on corrections for the vertical thinning of layers. During the past 216000 a, this $\mathrm{SMB}$ ratio, denoted $\mathrm{SMB}_{\mathrm{EDC}} / \mathrm{SMB}_{\mathrm{DF}}$, varied between 0.7 and 1.1, being small during cold periods and large during warm periods. Our results therefore reveal larger amplitudes of changes in SMB at EDC compared with DF, consistent with previous results showing larger amplitudes of changes in water stable isotopes and estimated surface temperature at EDC compared with DF. Within the last glacial inception (Marine Isotope Stages, MIS-5c and MIS-5d), the SMB ratio deviates by up to 0.2 from what is expected based on differences in water stable isotope records. Moreover, the SMB ratio is constant throughout the late parts of the current and last interglacial periods, despite contrasting isotopic trends.
\end{abstract}

KEYWORDS: ice cores, surface mass balance, vertical thinning, volcanic synchronization

\section{INTRODUCTION}

In the context of global warming and sea-level rise, changes in the mass balance of the ice sheets must be carefully monitored, understood and anticipated, as they could become the main contributor of sea-level rise in the coming centuries (Church and others, 2013). The mass balance of an ice sheet is approximately the sum of the surface mass balance (SMB) and the grounding line mass balance, both terms being uncertain in the context of global warming (Bengtsson and others, 2011; Rignot and others, 2014).

Present-day field monitoring and atmospheric reanalyses depict a year-round occurrence of rare snowfall events in central East Antarctica (e.g. Ekaykin, 2003; Fujita and Abe, 2006). Moisture back-trajectories identify ice core moisture sources located on average at $45^{\circ} \mathrm{S}$ today, but with a larger contribution of lower latitudes for the highest elevation, i.e. most inland sites (Masson-Delmotte and others, 2008; Suzuki and others, 2008; Sodemann and Stohl, 2009; Scarchilli and others, 2011). Different ice cores have different

* These authors contributed equally to this work. longitudinal origins of water vapor, depending on their location (Fig. 1). For instance, Dome $\mathrm{C}$ receives moisture predominantly from the Indian Ocean sector, while it is mostly advected from the Atlantic Ocean towards Dome F (e.g. Reijmer and others, 2002; Suzuki and others, 2008; Sodemann and Stohl, 2009). The SMB in Antarctica is also a function of the surface elevation of the ice sheet (e.g. Takahashi and others, 1994; Krinner and Genthon, 1999) and is affected by the redeposition of snow by wind (Gallée and others, 2012). For example, it is known that SMB differs between the windward and leeward sides of ice divides for strong-wind events (Fujita and others, 2011). In addition, local variations in the SMB are governed by the local surface topography, which is influenced by the bedrock topography (Fujita and others, 2011). Above the Antarctic plateau, accumulation is not only driven by maritime intrusions and snowfall events, but also by clear sky condensation, possibly related to boundary layer dynamics. Finally, it may also be affected by exchanges of water vapor between surface snow and the surrounding air (Hoshina and others, 2014). Such processes have been 


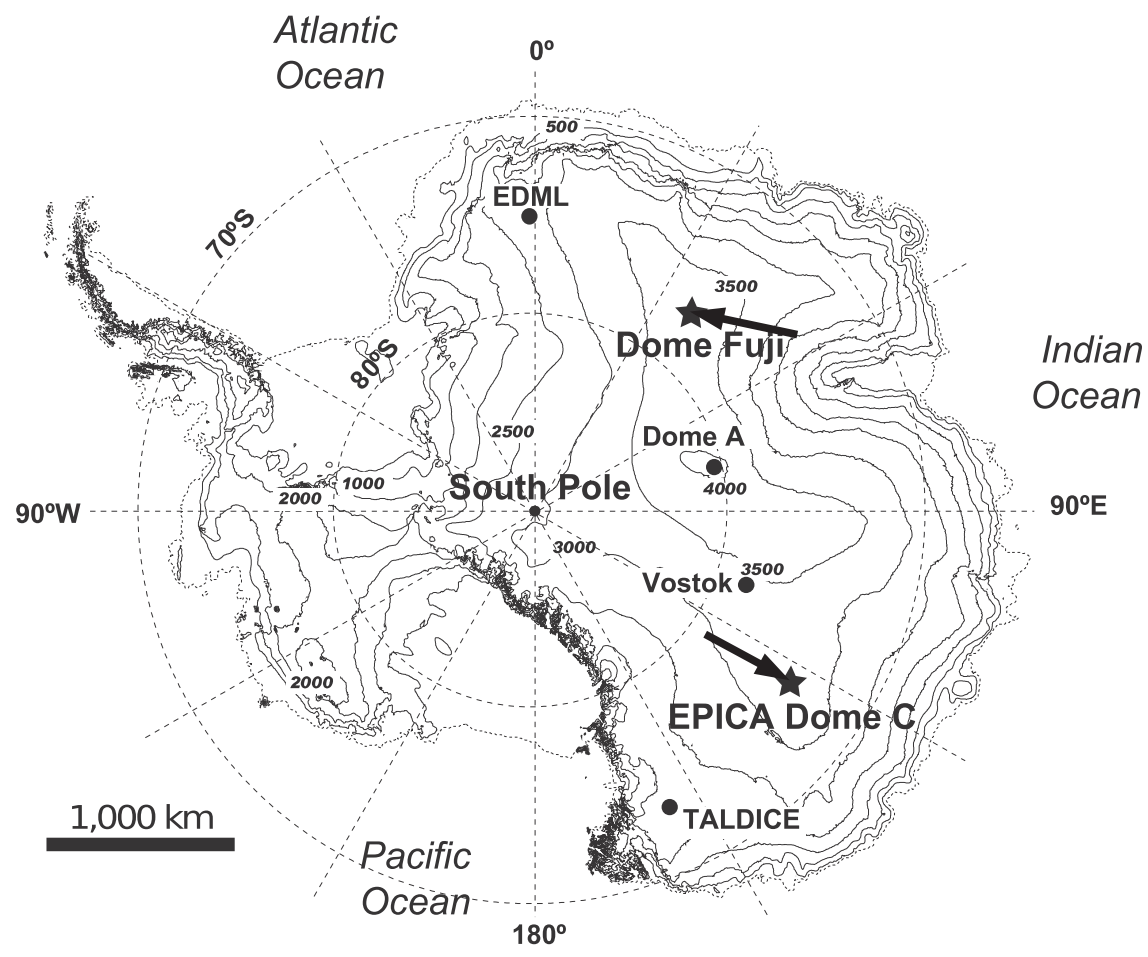

Fig. 1. Map of the Antarctic continent with elevation contours every $500 \mathrm{~m}$. The two ice coring sites used in this study, Dome C and DF, are marked with stars. Other ice coring sites mentioned in this paper are marked with filled circles. The prevailing wind directions at surface for both the Dome $\mathrm{C}$ and DF sites are indicated with arrows.

recently highlighted by diurnal variations in vapor isotopic composition both in Greenland (Steen-Larsen and others, 2014) and Antarctica (Ritter and others, 2016). Considering the exchanges of water vapor between surface snow and the surrounding air as well as snow transportation by wind, not only high-precipitation events associated with strong winds, but also daily exposure to prevailing wind, E-N-E at Dome Fuji (DF) and S at EPICA Dome C (EDC), may have significant effects on $\mathrm{SMB}$, water stable isotope ratios and snow properties at these dome sites.

Ice sheets also form a rich paleo-climatic archive. For dating (e.g. Kawamura and others, 2007; Parrenin and others, 2007) or interpreting the ice core records (e.g. transferring concentrations of species in ice into atmospheric fluxes; Wolff and others, 2006), an evaluation of the past $\mathrm{SMB}$ is needed. Indeed, the annual layer thickness along an ice core is the product of the initial SMB and the vertical thinning function accounting for the ice flow. Usually, past $\mathrm{SMB}$ is presumed to be exponentially related to the deuterium $\left(\delta \mathrm{D}_{\text {ice }}\right)$ or oxygen-18 $\left(\delta^{18} \mathrm{O}_{\text {ice }}\right)$ isotopic content of the ice. The underlying assumption is that condensation is proportional to the saturation vapor pressure of water in air, which itself is related to condensation temperature and therefore to precipitation isotopic composition (Jouzel and others, 1987; Parrenin and others, 2004, 2007; Masson-Delmotte and others, 2008). This approach has been applied to obtain past SMB estimates for deep ice cores after correcting the water stable isotope records for variations in the isotopic composition of the ocean, and/or for artifacts due to changes in moisture sources, using the second-order deuterium excess information (Stenni and others, 2001; Parrenin and others, 2007; Uemura and others, 2012).

Alternatively, constrains from ice core chronologies can be used to infer changes in layer thickness, which, after correction for thinning, provide information on past changes in SMB. For example, an alternative approach to estimating past $\mathrm{SMB}$ of polar ice sheets is to investigate ice-equivalent thickness between accurately dated reference horizons in the ice core stratigraphy, such as volcanic eruption markers, and to correct for vertical thinning. This approach is widely used to estimate the SMB of relatively shallow cores or snow pits (e.g. Frezzotti and others, 2013 and references therein). However, thus far, this approach has not been used for the enormous number of volcanic markers found in very deep ice cores because most of the volcanic markers in such ice cores have not been dated independently.

Here, we propose a similar approach to estimate the past ratio of SMB between DF and EDC, two remote dome sites in East Antarctica (Fig. 1). Deep ice cores drilled at the two sites were first synchronized by identifying 1401 volcanic tie points over a period covering the past $216 \mathrm{ka}$ (Fujita and others, 2015). Instead of dating these 1401 volcanic horizons independently, we derive changes in the relative thickness of the ice core sections covering the same time periods in the two cores. After correction of the mechanical thinning effects due to glacial flow, we are able to derive the SMB ratio between the two places. The thinning function is relatively straightforward to evaluate for these drilling sites located on domes, where horizontal advection is expected to be negligible. This new approach provides information on the relative SMB pattern of the East Antarctic ice sheet over glacial-interglacial cycles from the last $216 \mathrm{ka}$. We discuss how spatially inhomogeneous changes of the SMB may have occurred between the two remote dome sites.

\section{METHODS}

\subsection{The two studied ice core drilling sites}

DF and Dome C are two remote dome summits in East Antarctica located $\sim 2000 \mathrm{~km}$ apart (Table 1; Fig. 1). DF is located on the polar plateau facing the Atlantic and Indian 
Table 1. Information on the two drilling sites

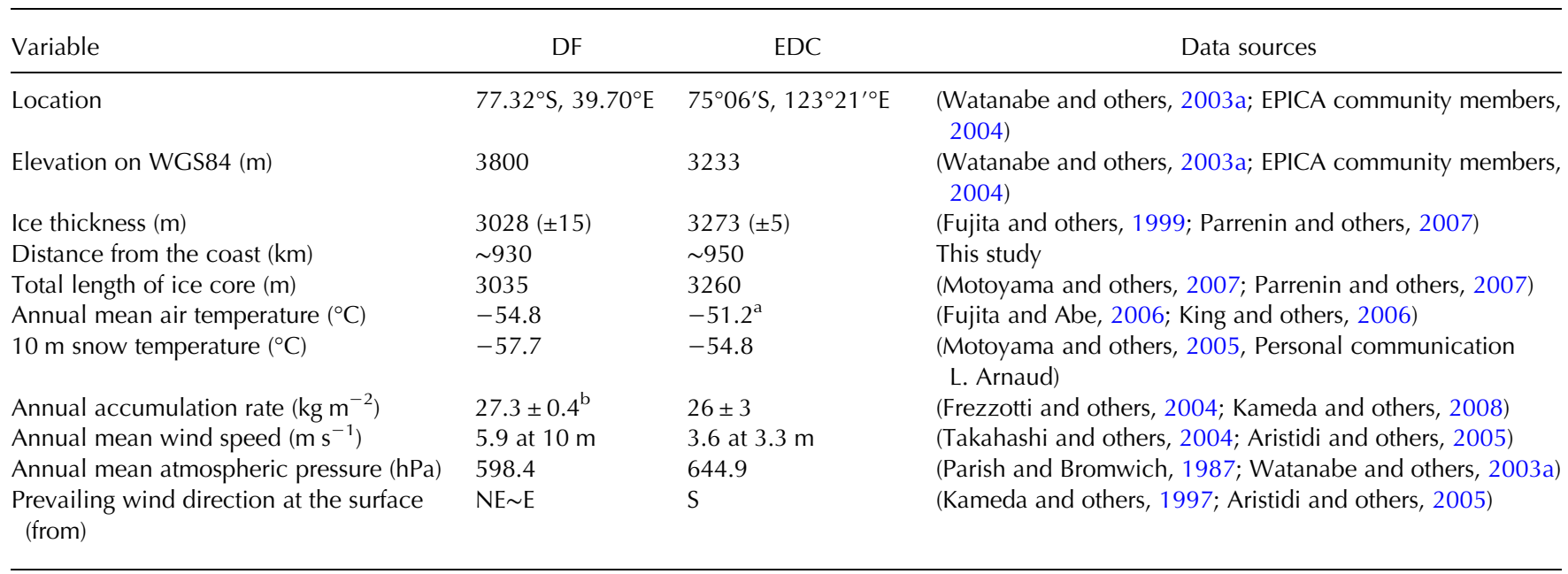

\footnotetext{
a Over the period 1984-2013.

b Snow stake farm.
}

Ocean sectors and is surrounded by the Dronning Maud Mountains, a coastal escarpment in particular along longitudes ranging from $\sim 20^{\circ} \mathrm{W}$ to $\sim 35^{\circ} \mathrm{E}$. At DF, prevailing wind direction is from the east (Table 1). Presently, DF shows a spatial gradient of SMB decreasing southwards (Fujita and others, 2011). High-precipitation events associated with strong winds from the NE direction have a major influence on the SMB (Fujita and Abe, 2006), but no seasonality of precipitation has been noted (Fujita and Abe, 2006; Kameda and others, 2008).

Dome $\mathrm{C}$ is located at one of the dome summits in East Antarctica in the Indian Ocean sector and the moisture predominantly comes from the Indian Ocean. Its elevation is lower than that of DF by $\sim 570 \mathrm{~m}$. This part of the East Antarctic ice sheet has a gentler slope from the coast to polar plateau compared with the escarpment surrounding DF (Fig. 1). Reflecting the shape of the East Antarctic ice sheet, prevailing surface winds are from the south, that is, from continental inland; surface winds rarely occur from the west, north or east directions (Aristidi and others, 2005).

It should first be noted that at present, DF is higher by $600 \mathrm{~m}$, slightly colder, and has 30\% more depleted surface snow $\delta$ D than EDC (Table 1; Fig. 1). The EDC-DF isotopic differences cannot be explained by differences in surface temperature or relationships with accumulation, based on Rayleigh distillation relationships. The DF-EDC deuterium difference would require $6^{\circ} \mathrm{C}$ difference in condensation temperature to be accounted for, based on the spatial isotope/temperature relationship (Jouzel and Merlivat, 1984). In fact, possible explanations for such an isotopic difference are linked with the origin of precipitation (MassonDelmotte and others, 2011), with differences in condensation temperature, with precipitation seasonality and/or intermittency (Masson-Delmotte and others, 2011), with surface snow/vapor interactions (Hoshina and others, 2014; SteenLarsen and others, 2014) or with elevation differences between the two sites. The more depleted modern value of $\delta \mathrm{D}_{\text {ice }}$ at DF may for instance be explained by a higher proportion of precipitation occurring during winter at this site compared with EDC (but we have no observational evidence to confirm this hypothesis at the moment) or by a more remote moisture source, as expected from the wider winter expansion of sea ice in the Atlantic compared with the Indian Ocean sector (Gersonde and others, 2005).
At each of the two sites, two long ice cores have been drilled. At DF, the first core (DF1) was drilled in 1992-98 to a depth down to $2503 \mathrm{~m}$ (Watanabe and others, 2003a). The second $3035 \mathrm{~m}$ long core (DF2), reaching almost to the ice-sheet bed, was drilled in 2004-07, at a site $\sim 43 \mathrm{~m}$ from the DF1 borehole (Motoyama, 2007). At Dome C, the first core (EDC96) was started in the 1996/97 season to a depth of $790 \mathrm{~m}$. The second $3270 \mathrm{~m}$ long core (EDC99) reaching nearly the ice-sheet bed, was started during the $1999 / 2000$ season at a site $10 \mathrm{~m}$ away from the EDC96 core (EPICA community members, 2004). Ice core signals from these four cores have been used here for volcanic synchronization.

Here we use as a reference chronology the DFO-2006 timescale established for the DF ice core (Kawamura and others, 2007). This age scale is only used to plot quantities versus age, but has no impact on the reconstruction of the $\mathrm{SMB}_{\mathrm{EDC}}$ $\mathrm{SMB}_{\mathrm{DF}}$ ratio. Comparisons between chronologies for DF and EDC cores are discussed by Fujita and others (2015).

\subsection{EDC-DF volcanic synchronization and synchro- based $\mathrm{SMB}_{\mathrm{EDC}} / \mathrm{SMB}_{\mathrm{DF}}$ ratio}

The EDC-DF volcanic matching consists of 1401 depth tie points (Fujita and others, 2015), down to a depth of $2184 \mathrm{~m}$ at DF and $2170 \mathrm{~m}$ at EDC, which roughly corresponds to an age of $216 \mathrm{ka}$ in the DFO-2006 chronology (Kawamura and others, 2007). On average, that makes one tie point every $154 \mathrm{a}$, although their distribution is irregular (Fig. 2). For the periods of MIS 3, 5a and 5b-5e, a large number of tie points were found, typically one every 50$100 \mathrm{a}$. Identifying unequivocal tie points was difficult in some cold periods such as MIS 2, 4, 5b and 6. For volcanic signals, ECM, DEP and sulfate data were used for EDC, and ECM and ACECM data were used for DF. More details on the synchronization are given by Fujita and others (2015). These tie points were then placed on an age scale (DFO2006) and re-interpolated every ka. The ratio of layer thickness at EDC and DF of these 1 ka-long intervals $\Delta z_{\mathrm{EDC}}$ $\Delta z_{\text {DF }}$ can be inferred (Figs 2 and 3). We refer to it as the layer thickness ratio.

Vertical thinning $\tau$ due to ice flow has been estimated both for the EDC and DF ice cores based on a one-dimensional (1-D) ice flow model (Parrenin and others, 2007) with a 


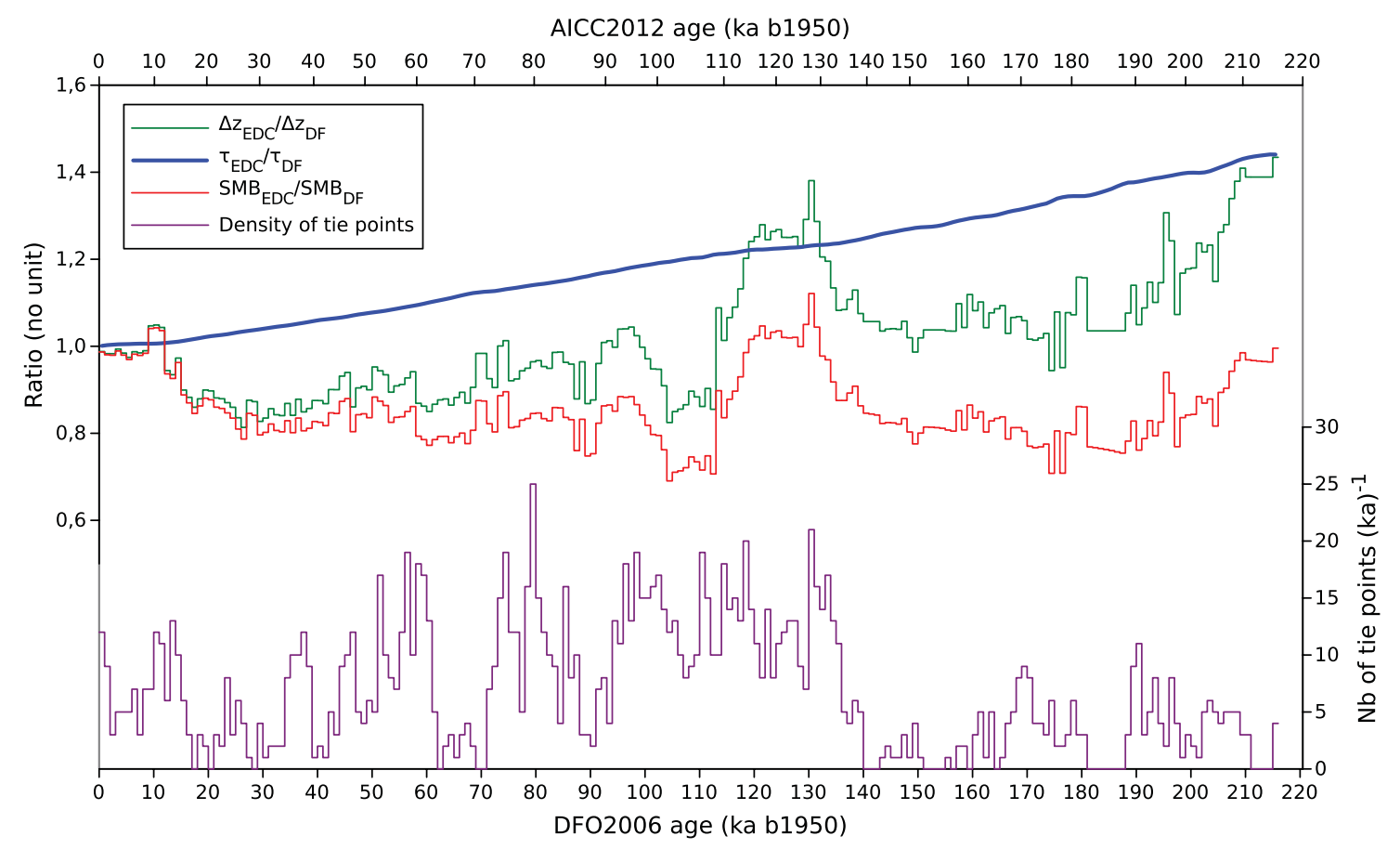

Fig. 2. Ratio of layer thickness (green) or surface mass balance (red) after correcting for the EDC-DF thinning ratio (blue). The density of tie points (violet) is indicated in the lower panel (No. of tie points ka ${ }^{-1}$ ). The DFO-2006 (Kawamura and others, 2007) and AICC2012 (Bazin and others, 2013; Veres and others, 2013) age scales are indicated.

\section{EDC}

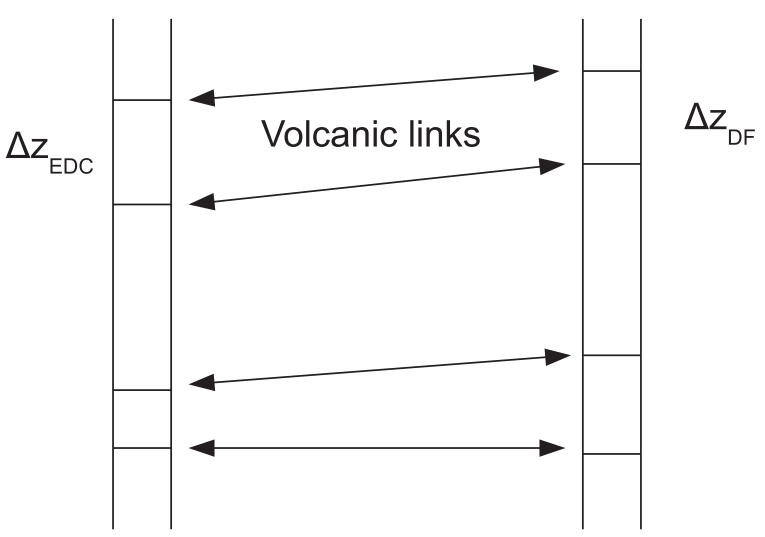

Fig. 3. Scheme illustrating the derivation of the $\Delta z_{\mathrm{EDC}} / \Delta z_{\mathrm{DF}}$ ratio from the volcanic links in between the EDC and DF ice cores.

prescribed analytical velocity profile (Lliboutry, 1979) and a prescribed ice thickness evolution based on a 3-D model of Antarctic evolution (Ritz and others, 2001). The thinning ratio between EDC and DF $\tau_{\mathrm{EDC}} / \tau_{\mathrm{DF}}$ is 1 for the present-day and increases up to $\sim 1.5$ at $200 \mathrm{ka}$ (high thinning ratios imply that EDC thins less than DF), which is mainly due to the fact that the ice thickness is larger at EDC than DF (Table 1). After correcting the layer thickness ratio $\Delta z_{\mathrm{EDC}}$ $\Delta z_{\mathrm{DF}}$ by the vertical thinning effects, we obtain a synchrobased $\mathrm{SMB}_{\mathrm{EDC}} / \mathrm{SMB}_{\mathrm{DF}}$ ratio (Fig. 2).

\subsection{Surface temperature and mass balance at EDC and DF}

A simple Rayleigh model can link the variations of the isotopic composition of vapor in an air mass with the variations of its temperature (Dansgaard, 1964). Estimates of surface temperature can therefore be evaluated from the isotopic content of the ice $\delta^{18} \mathrm{O}_{\text {ice }}$ and $\delta \mathrm{D}_{\text {ice, }}$ first corrected for the temporal variations in isotopic content of the ocean $\delta^{18} \mathrm{O}_{\mathrm{sw}}$ and $\delta \mathrm{D}_{\text {sw }}$ (Jouzel and others, 2003):

$$
\begin{gathered}
\delta^{18} \mathrm{O}_{\text {corr }}=\delta^{18} \mathrm{O}_{\text {ice }}-\delta^{18} \mathrm{O}_{\mathrm{sw}} \frac{1+\delta^{18} \mathrm{O}_{\text {ice }}}{1+\delta^{18} \mathrm{O}_{\mathrm{sw}}}, \\
\delta \mathrm{D}_{\text {corr }}=\delta \mathrm{D}_{\text {ice }}-\delta \mathrm{D}_{\mathrm{SW}} \frac{1+\delta \mathrm{D}_{\text {ice }}}{1+\delta \mathrm{D}_{\mathrm{sW}}}
\end{gathered}
$$

$\delta^{18} \mathrm{O}_{\mathrm{Sw}}$ is taken as reconstructed by Bintanja and others (2005) based on the exhaustive LR04 oceanic stack (Lisiecki and Raymo, 2005). $\delta \mathrm{D}_{\mathrm{SW}}$ is calculated on the assumption that $\delta \mathrm{D}_{\mathrm{SW}}=8 \delta^{18} \mathrm{O}_{\mathrm{sw}}$. From this, we derive a first reconstruction of accumulation, called ocean-corrected (Fig. 4):

$$
\mathrm{a}_{\mathrm{oc}}=A^{0} \exp \left(\beta\left(\delta \mathrm{D}_{\text {corr }}-\delta \mathrm{D}_{\text {corr }}^{0}\right)\right)
$$

with $\beta=0.015, \delta \mathrm{D}_{\text {corr }}^{0}=-390.9 \%$ and $A^{0}=3.1 \mathrm{~cm}^{\text {(ice) } \mathrm{a}^{-1}}$ for $\mathrm{EDC}$ and $\beta=0.013, \delta \mathrm{D}_{\mathrm{corr}}^{0}=-403.1 \%$ and $A^{0}=3.8 \mathrm{~cm}$ (ice) $\mathrm{a}^{-1}$ for DF. The values of these parameters were chosen for a best fit (Fig. 4) with the published accumulation reconstructions that are compatible with the age scales of the two cores (Parrenin and others, 2007). The ratio of these reconstructed $\mathrm{SMB}$ histories is hereafter named ocean-corrected $\mathrm{SMB}_{\mathrm{EDC}} / \mathrm{SMB}_{\mathrm{DF}}$ ratio.

SMB estimates can be refined by correcting the water stable isotope records for variations in the temperature of the ocean where the moisture forms and/or for artifacts due to changes in moisture sources using the second-order deuterium excess record. Site and source temperature estimates over time $\Delta T_{\text {site }}$ and $\Delta T_{\text {source }}$ can be deduced using a set of two linear equations (Stenni and others, 2001; Uemura and 


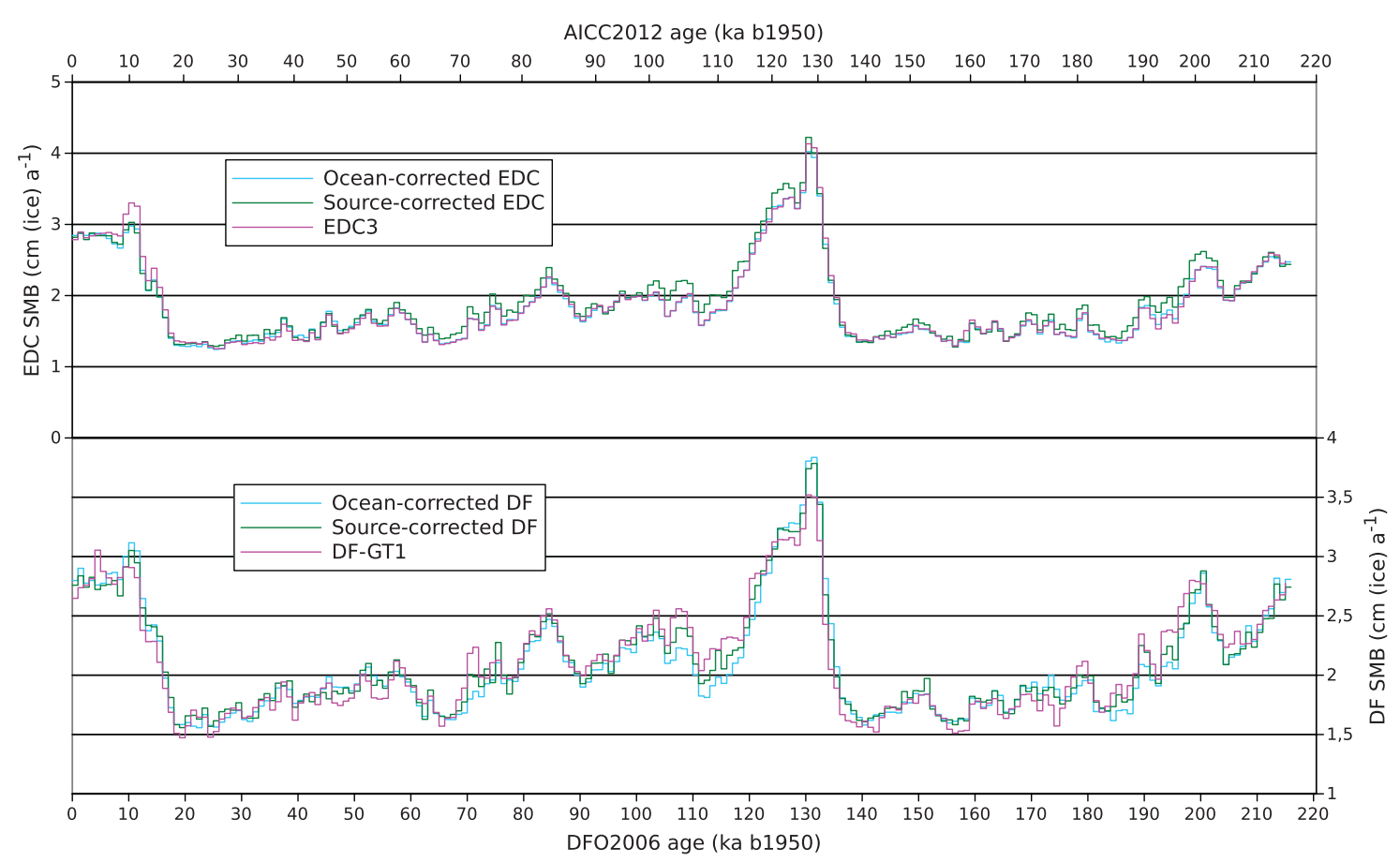

Fig. 4. Comparison of various accumulation reconstructions for the EDC and DF ice cores: ocean-corrected (light blue), source-corrected (green) and published (pink, Parrenin and others, 2007).

others, 2012):

$$
\begin{gathered}
\delta \mathrm{D}_{\text {corr }}-\delta \mathrm{D}_{\text {corr }}^{0}=\gamma_{\text {site }} \Delta T_{\text {site }}-\gamma_{\text {source }} \Delta T_{\text {source }}, \\
d_{\text {corr }}-d_{\text {corr }}^{0}=-\beta_{\text {site }} \Delta T_{\text {site }}+\beta_{\text {source }} \Delta T_{\text {source }}
\end{gathered}
$$

where $d_{\text {corr }}$, the corrected deuterium excess, is $d_{\text {corr }}=\delta \mathrm{D}_{\text {corr }}-$ $8 \delta^{18} \mathrm{O}_{\text {corr }}$. The coefficients of Eqs. $(4,5)$, namely $\gamma_{\text {site, }} \gamma_{\text {source, }}$ $\beta_{\text {site }}$ and $\beta_{\text {source, }}$ have been previously inferred at both sites using a simple Rayleigh-based model, constrained with present-day surface data on the trajectories of air masses and their values can be found in Uemura and others (2012). Site temperature is calculated from $\Delta T_{\text {site }}$ using the $10 \mathrm{~m}$ snow temperature (Table 1 ) as the average temperature for the 0-1 ka b1950 interval. From this, we derive a second accumulation reconstruction, called source-corrected (Fig. 4), which is not based directly on $\delta \mathrm{D}_{\text {ice }}$ but on the source-corrected site temperature reconstruction:

$$
a_{\text {sc }}=A^{0} \exp \left(\beta\left(\gamma_{\text {site }}-\beta_{\text {site }} \frac{\gamma_{\text {source }}}{\beta_{\text {source }}}\right) \Delta T_{\text {site }}\right),
$$

which translates into:

$\mathrm{a}_{\mathrm{sC}}=A^{0} \exp \left(\beta\left(\left(\delta \mathrm{D}_{\text {corr }}-\delta \mathrm{D}_{\text {corr }}^{0}\right)+\frac{\gamma_{\text {source }}}{\beta_{\text {source }}}\left(d_{\text {corr }}-d_{\text {corr }}^{0}\right)\right)\right)$,

with $\beta=0.016, \delta \mathrm{D}_{\text {corr }}^{0}=-390.9 \%$, $d_{\text {corr }}^{0}=10.1 \%$ and $A^{0}=$ $3.2 \mathrm{~cm}$ (ice) $\mathrm{a}^{-1}$ for $\mathrm{EDC}$ and $\beta=0.015, \delta \mathrm{D}_{\text {corr }}^{0}=-403.1 \%$, $d_{\text {corr }}^{0}=13.4 \%$ and $A^{0}=3.7 \mathrm{~cm}$ (ice) $\mathrm{a}^{-1}$ for DF. The values of these parameters were chosen for a best fit (Fig. 4) with the published accumulation reconstructions that are compatible with the age scales of the two cores (Parrenin and others, 2007). The ratio of these reconstructed SMB histories is hereafter named source-corrected $\mathrm{SMB}_{\mathrm{EDC}} / \mathrm{SMB}_{\mathrm{DF}}$ ratio.
The formulas that we used here for temperature reconstructions are the same as in Uemura and others (2012), but slightly different from those used by Parrenin and others (2007). At the time of this second study, EDC deuterium excess was not available, and therefore the accumulation was only inferred from the deuterium data after ocean correction. Here, we use the EDC deuterium excess data (Stenni and others, 2010) to provide a coherent approach for the two sites.

\subsection{Simplified ice thickness models at EDC and DF}

Ice thickness variations on the East Antarctic plateau can be mainly explained by variations in surface accumulation (Parrenin and others, 2007). To test the implications of various accumulation reconstructions on the ice thickness history at the two sites, we used a 1-D conceptual model (Parrenin and others, 2007) fitted onto 3-D simulations (Ritz and others, 2001). This model is a simple linear perturbation model, where the vertical velocity of ice at surface with respect to bedrock is written:

$$
a-\frac{\partial H}{\partial t}=k+k_{\mathrm{H}} H+k_{\mathrm{S}} S
$$

and where the bedrock follows a simple relaxation law to an equilibrium:

$$
\frac{\partial B}{\partial t}=\frac{\left(B_{0}-H / k_{\mathrm{B}}\right)-B}{\tau_{\mathrm{B}}},
$$

where $a$ is the accumulation rate, $B$ is the bedrock elevation, $H$ is the ice thickness, $S=B+H$ is the surface elevation of the ice sheet, and $k, k_{\mathrm{H}}, k_{\mathrm{S}}, k_{\mathrm{B}}, B_{0}$ and $\tau_{\mathrm{B}}$ are parameters, whose values for EDC and DF are given in Table 2 of Parrenin and others (2007). $B_{0}$ corresponds to a bedrock elevation without isostatic effect. There is a systematic bias of the model toward lower elevation. Therefore, we only consider the elevation changes with respect to the present. 


\section{RESULTS}

\subsection{Synchro-based $S M B_{E D C} / S M B_{D F}$ ratio and comparison with the $\delta \mathrm{D}$ records}

The ratio of layer thickness $\Delta z_{\mathrm{EDC}} / \Delta \mathrm{z}_{\mathrm{DF}}$ inferred from the volcanic synchronization (Fig. 2, green curve) exhibits an increasing trend towards the past. We correct the layer thickness ratio for the vertical thinning ratio as deduced from ice flow modeling at both sites (Fig. 2, blue curve) and obtain the $S M B_{E D C} / S M B_{D F}$ ratio (Fig. 2, orange curve).

Our synchro-based $\mathrm{SMB}_{\mathrm{EDC}} / \mathrm{SMB}_{\mathrm{DF}}$ ratio depicts large variations of up to 0.4 . These variations resemble the variations of the $\delta \mathrm{D}_{\text {ice }}$ profiles. The correlation coefficient is 0.74 between the average deuterium profile at EDC and DF and the $S M B_{E D C} / S M B_{D F}$ ratio for 1 ka re-sampled time series. Figure 5 suggests a correlation for minor troughs and peaks, as indicated by the thin black vertical dashed lines, although the correlation is not systematic. For example, during the early optimum of the last interglacial period occurring at $\sim 128$ ka on the DFO-2006 age scale, our method reconstructs $S M B_{E D C} / S M B_{D F}$ ratio to be 1.1. However, there are also periods when no relationship between $\mathrm{SMB}_{\mathrm{EDC}} / \mathrm{SMB}_{\mathrm{DF}}$ and $\delta \mathrm{D}_{\text {ice }}$ is observed. This is the case during the glacial inception cooling (MIS 5d and 5c). Indeed, the lowest values of the synchro-based $\mathrm{SMB}_{\mathrm{EDC}} / \mathrm{SMB}_{\mathrm{DF}}$ ratio $(0.7)$ are reached for MIS $5 \mathrm{~d}-5 \mathrm{c}$, while the lowest values of the $\delta \mathrm{D}_{\text {ice }}$ profiles are reached at the Last Glacial Maximum (LGM).

We now focus on the present and last interglacial periods. We first observe that the synchro-based $\mathrm{SMB}_{\mathrm{EDC}} / \mathrm{SMB} \mathrm{B}_{\mathrm{DF}}$ is stable during the late part of the interglacial periods (125-118 and 8-0 ka b1950), despite different $\delta \mathrm{D}$ trends (a long-term decrease at DF versus stable levels at EDC). Second, we note very similar levels in the synchro-based $\mathrm{SMB}_{\mathrm{EDC}} / \mathrm{SMB} \mathrm{B}_{\mathrm{DF}}$ during the present and during the warmer last interglacial period.

\subsection{Comparison of the synchro-based and isotope- based $\mathrm{SMB}_{\mathrm{EDC}} / \mathrm{SMB}_{\mathrm{DF}}$ ratios}

The synchro-based and isotope-based (ocean-corrected and source-corrected) $\mathrm{SMB}_{\mathrm{EDC}} / \mathrm{SMB}_{\mathrm{DF}}$ ratios are compared in Figure 5. The large-scale variations of all SMB ratios display glacial-interglacial variations. The source correction has only a minor effect when compared with the ocean-corrected $\mathrm{SMB}_{\mathrm{EDC}} / \mathrm{SMB}_{\mathrm{DF}}$, with differences generally $<0.1$. The differences are larger between the synchro-based and isotopebased $\mathrm{SMB}_{\mathrm{EDC}} / \mathrm{SMB}_{\mathrm{DF}}$ ratios. In particular during MIS $5 \mathrm{~d}$ and $5 c$, the difference reaches 0.2 , the synchro-based $\mathrm{SMB}_{\mathrm{EDC}} / \mathrm{SMB}_{\mathrm{DF}}$ ratio being less than what can be inferred based on water isotopes. The difference also reaches 0.1 for periods at 60 and $90 \mathrm{ka} \mathrm{b1950.} \mathrm{Another} \mathrm{noticeable} \mathrm{difference}$ is that the synchro-based $\mathrm{SMB}_{\mathrm{EDC}} / \mathrm{SMB} \mathrm{B}_{\mathrm{DF}}$ ratio displays peaks at the beginning of the Holocene and Eemian periods while the isotope-based $\mathrm{SMB}_{\mathrm{EDC}} / \mathrm{SMB} \mathrm{B}_{\mathrm{DF}}$ ratios do not.

\subsection{Consequences on elevation variations and thinning functions}

As Parrenin and others (2007) have shown, the thinning function is influenced by the elevation variations at the drilling sites, which is itself influenced by accumulation variations. We can therefore ask ourselves how robust are the thinning functions that we used to calculate the synchro-based $\mathrm{SMB}_{\mathrm{EDC}} / \mathrm{SMB}_{\mathrm{DF}}$ ratio. For EDC, we calculate an alternative

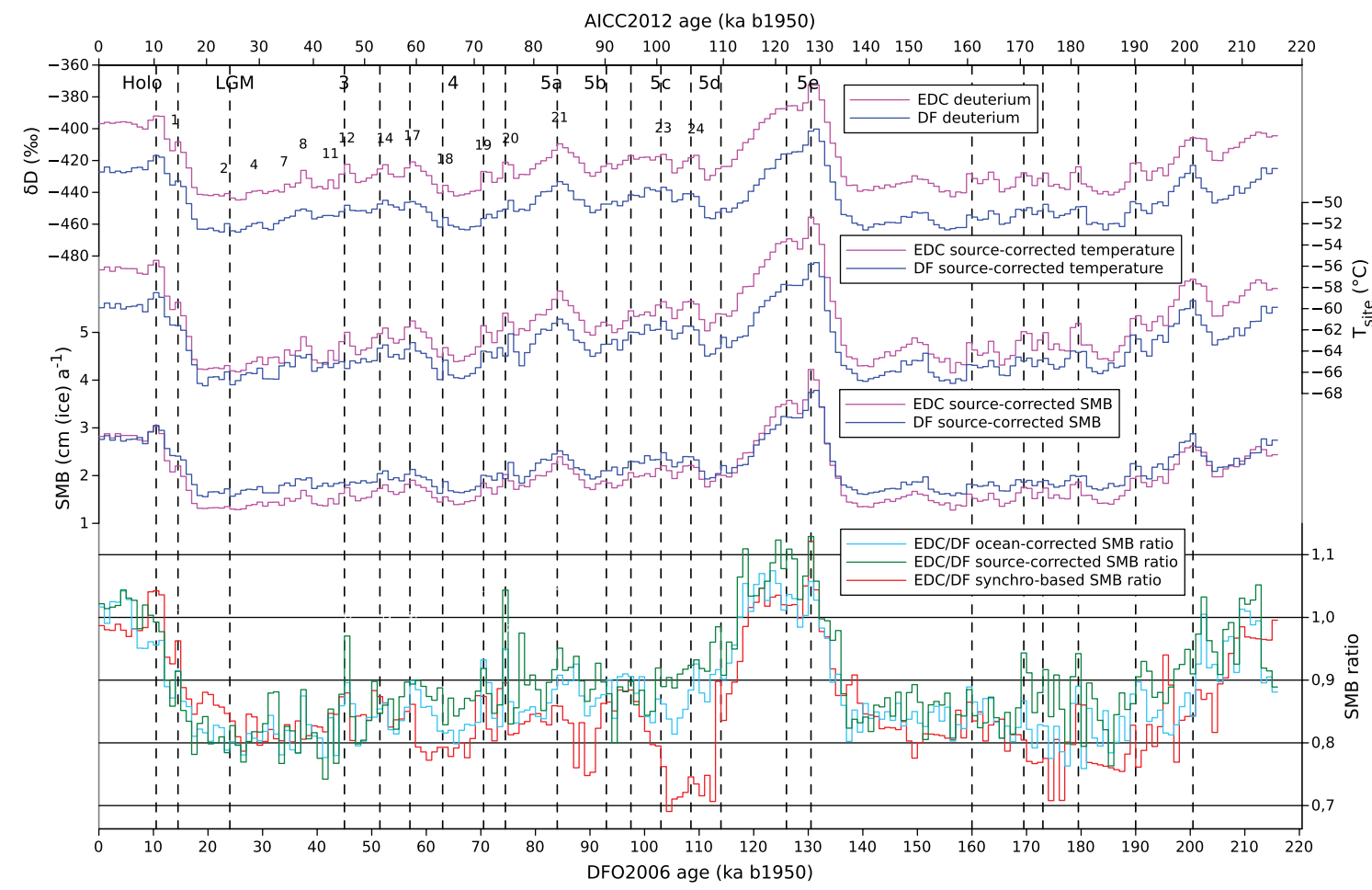

Fig. 5. (top) DF (Watanabe and others, 2003a) (blue) and EDC (Jouzel and others, 2007) (pink) $\delta$ D ice variations. Top labels indicate the Marine Isotope Stages and bottom labels indicate the Antarctic Isotopic Maxima (AIMs) events. (middle top) DF (blue) and EDC (pink) source-corrected T site reconstructions (this study). (middle bottom) DF (blue) and EDC (pink) source-corrected surface accumulation rate (this study). (bottom) Ratio of ocean-corrected (light blue), source-corrected (green) and synchro-based (red) surface mass balances. The DFO-2006 (Kawamura and others, 2007) and AICC2012 age scales (Bazin and others, 2013; Veres and others, 2013) are used. The thin vertical black dashed lines mark correspondences in millennial scale events. Note that we did not plot the ratio of the published SMBs at EDC and DF (Parrenin and others, 2007), since they used inconsistent formulas (Section 2). 
accumulation reconstruction by multiplying the sourcecorrected $\mathrm{SMB}_{\mathrm{DF}}$ by our synchro-based $\mathrm{SMB}_{\mathrm{EDC}} / \mathrm{SMB} \mathrm{B}_{\mathrm{DF}}$ ratio. We call this the synchro-based $\mathrm{SMB}_{\mathrm{EDC}}$. Similarly, we calculate the synchro-based $\mathrm{SMB}_{\mathrm{DF}}$ by dividing the sourcecorrected $\mathrm{SMB}_{\mathrm{EDC}}$ by our synchro-based $\mathrm{SMB}_{\mathrm{EDC}} / \mathrm{SMB}_{\mathrm{DF}}$ ratio. Then we calculate the elevation variations at EDC and DF from our conceptual model described in Section 2 and from the source-corrected or synchro-based SMB scenarios.

The results are displayed on Figure 6. For both EDC and DF, the two accumulation scenarios lead to the same qualitative features, with an ice thickness smaller during glacial periods and higher during interglacial periods. For EDC, the LGM ice thickness is $\sim 160 \mathrm{~m}$ (resp. $\sim 150 \mathrm{~m}$ ) lower than the presentday thickness for the source-corrected (resp. synchro-based) SMB scenario. The standard deviation of the difference between both scenarios is $\sim 10.5 \mathrm{~m}$. The largest difference is $\sim 35 \mathrm{~m}$ for MIS5d, i.e. $\sim 1 \%$ of the ice thickness. For DF, the LGM ice thickness is $\sim 145 \mathrm{~m}$ (resp. $\sim 160 \mathrm{~m}$ ) lower than the present-day thickness for the source-corrected (resp. synchro-based) SMB scenario. The standard deviation of the difference between both scenarios is $\sim 14.5 \mathrm{~m}$. The largest difference is $\sim 60 \mathrm{~m}$ for MIS5d, i.e. $\sim 2 \%$ of the ice thickness.

\section{DISCUSSIONS}

\subsection{Reliability of the thinning corrections and of the volcanic match}

A first argument for the reliability of the thinning evaluation comes from the fact that the $S M B_{E D C} / S M B_{D F}$ curve, after the thinning correction, has a negligible decreasing trend toward the past. Indeed, we do not expect the $\mathrm{SMB}_{\mathrm{EDC}}$ $\mathrm{SMB}_{\mathrm{DF}}$ ratio to have a trend over several glacial-interglacial cycle. This suggests that the main trends of the thinning functions at EDC and DF have been captured by the ice flow models. The part of the $\Delta z_{\mathrm{EDC}} / \Delta z_{\mathrm{DF}}$ curve that varies at the glacial/interglacial scale, could also be due in part to the vertical thinning, with glacial layers relatively more thinned at EDC, and not correctly accounted for in the ice flow modeling exercises that we used. There is indeed a correlation between climate and some ice physical properties, such as fabric (Durand and others, 2009) or impurities (Watanabe and others, 2003b; Fujita and others, 2015), which can have an impact on ice flow properties. However, this hypothesis seems unlikely for several reasons. First, by mass conservation, an abnormally thinned layer at some place can only be explained if this layer is abnormally thickened at a neighboring place, but no irregularity is observed in the isochronal layers observed by ice sounding radars at DF (Fujita and others, 1999, 2012) or EDC (Siegert and others, 1998; Tabacco and others, 1998; Cavitte and others, 2016). Second, if glacial ice is softer than interglacial ice, the relative difference in cumulated vertical thinning with interglacial ice should increase with the age of the ice layers, as is shown by mechanical simulations (Durand and others, 2007), but no such effect is observed in the $\Delta z_{E D C} / \Delta z_{D F}$ curve. Third, mechanical simulations do not suggest that ice layers with different viscosities can lead to a very irregular thinning function (Durand and others, 2007). As outlined in Section 3, the
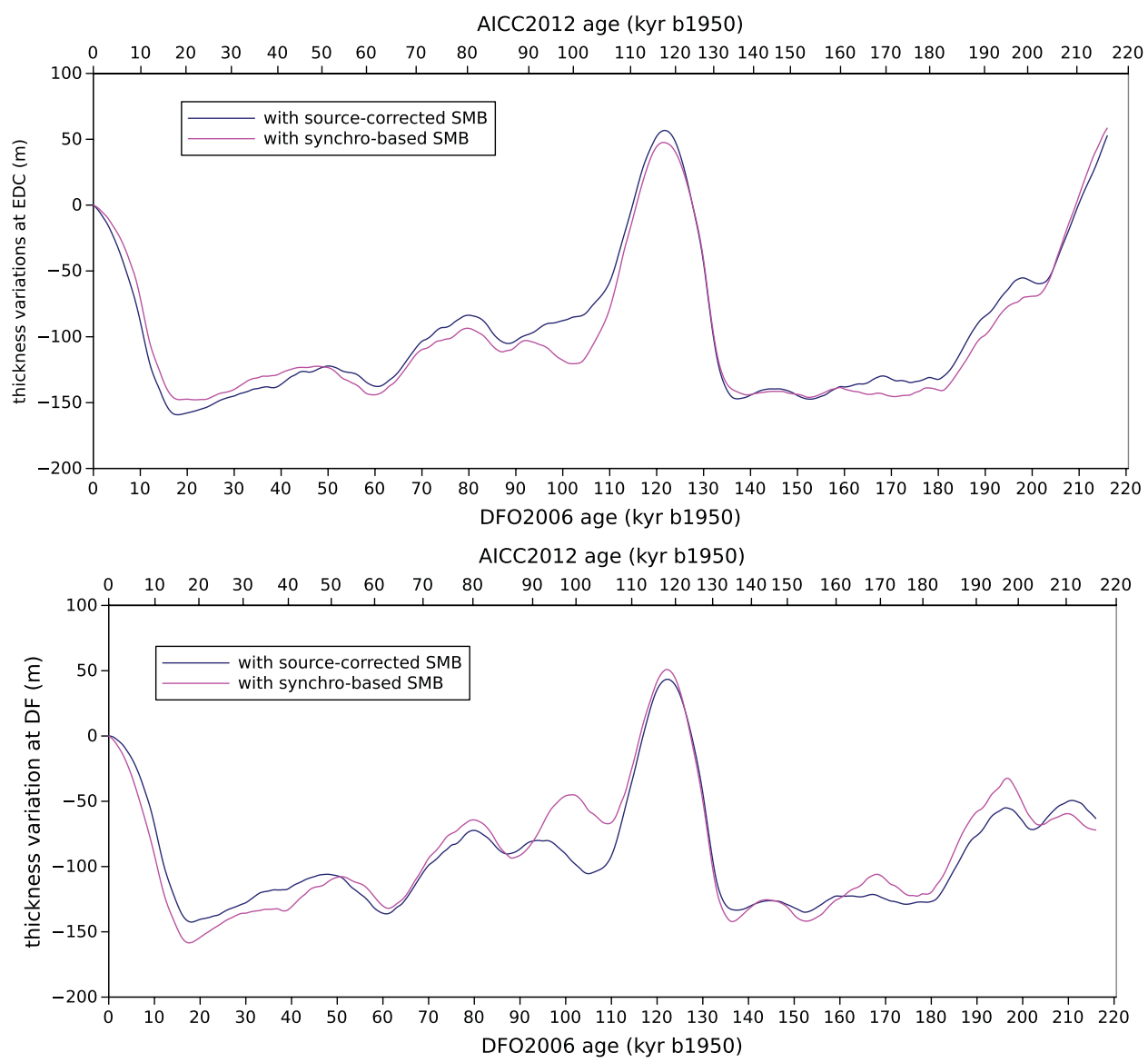

Fig. 6. Elevation variations at EDC (top) and DF (bottom) based on two different scenarios of SMB variations: source-corrected (blue) and synchro-based (pink). 
ice thickness reconstructions at EDC and DF are also partially uncertain due in particular to uncertainties in the accumulation scenarios. These relative uncertainties on the ice thickness scenarios of $\sim 1 \%$ for EDC and $\sim 2 \%$ for DF lead to approximately the same relative uncertainties on the thinning functions. This can explain neither the glacial-interglacial variations of the synchro-based $\mathrm{SMB}_{\mathrm{EDC}} / \mathrm{SMB} \mathrm{BF}_{\mathrm{DF}}$ ratio of up to 0.4 , nor the 0.2 difference between the source-corrected and synchro-based $\mathrm{SMB}_{\mathrm{EDC}} / \mathrm{SMB} \mathrm{B}_{\mathrm{DF}}$ ratios at $\mathrm{MIS} 5 \mathrm{~d}$. Finally, the interplay between the dome movement and the different strain rates at different locations could lead to irregularities in the thinning function. Indeed, the strain regime is different right at a dome than a few kilometers downstream on a flank due to the Raymond effect (Raymond, 1983) and the strain regime is also a function of the ice thickness. But there is no obvious reason why these effects would lead to a thinning function correlated with the deuterium profiles.

These elements therefore suggest that the main characteristics of our synchro-based $S M B_{E D C} / S M B_{D F}$ ratio are not due to error in the evaluations of the thinning functions at both sites. However, we can expect some errors in the modeling of the thinning functions at both sites to affect the details of our synchro-based $\mathrm{SMB}_{\mathrm{EDC}} / \mathrm{SMB} \mathrm{B}_{\mathrm{DF}}$ ratio. For example, as outlined previously, the error in the $\mathrm{SMB}$ reconstruction used at both sites to model the thinning functions (Parrenin and others, 2007) can affect ice-sheet thickness evaluation by $\sim 2 \%$ at maximum, which translates into a $2 \%$ error in the thinning function. Also, spatial variations in the ice thickness around both drilling sites can affect the thinning functions if the ice flow is not purely vertical (Parrenin and others, 2004). This is, however, difficult to assess since we do not have robust estimates of the dome movements during the past.

The robustness of the volcanic match used to deduce the synchro-based $\mathrm{SMB}_{\mathrm{EDC}} / \mathrm{SMB} \mathrm{BF}_{\mathrm{DF}}$ ratio can also be discussed, especially during the 105-113 ka b1950 time interval (MIS $5 \mathrm{c}$ and $5 \mathrm{~d}$ ), when the synchro-based and isotope-based $\mathrm{SMB}_{\mathrm{EDC}} / \mathrm{SMB} \mathrm{B}_{\mathrm{DF}}$ ratios deviate by as much as 0.2. Given the number of tie points in this interval (95), it seems very unlikely that the volcanic match is entirely wrong. Moreover, if the low values of the synchro-based $\mathrm{SMB}_{\mathrm{EDC}} / \mathrm{SMB}_{\mathrm{DF}}$ ratio during this time period were due to an incorrect volcanic match, it would be compensated by too high values before $105 \mathrm{ka}$ b1950 or after $113 \mathrm{ka} \mathrm{b1950.} \mathrm{But} \mathrm{no} \mathrm{such} \mathrm{high} \mathrm{values} \mathrm{are}$ observed, suggesting that an incorrect volcanic match is not the cause of the synchro-based and isotope-based $\mathrm{SMB}_{\mathrm{EDC}} / \mathrm{SMB}_{\mathrm{DF}}$ ratios difference during this time period. Moreover, we tried to guide our volcanic match during this time interval, so that the synchro-based $\mathrm{SMB}_{\mathrm{EDC}} / \mathrm{SMB}_{\mathrm{DF}}$ ratio would be in agreement with the isotope-based $\mathrm{SMB}_{\mathrm{EDC}} / \mathrm{SMB}_{\mathrm{DF}}$ ratios, but no satisfying volcanic match could be achieved.

Sulfate (Watanabe and others, 2003b; Wolff and others, 2006; lizuka and others, 2012) and beryllium-10 (Cauquoin and others, 2015) have been proposed to have a nearly temporally constant flux above Antarctica and could be used for an independent check of our synchro-based $\mathrm{SMB}_{\mathrm{EDC}} / \mathrm{SMB}_{\mathrm{DF}}$ ratio. Among those two, only sulfate is available for our studied time period and for both EDC (Wolff and others, 2006) and DF (Watanabe and others, 2003b; lizuka and others, 2012). Unfortunately, it appears that the sulfate flux is not constant enough at DF (lizuka and others, 2012; Figure $2 \mathrm{~d}$ ) for sulfate dilution to be a useful SMB proxy.

\subsection{Relative change of $S M B$ and relative change of local temperature}

Glacial climatic conditions coincide with a reduced synchrobased $\mathrm{SMB}_{\mathrm{EDC}} / \mathrm{SMB} \mathrm{B}_{\mathrm{DF}}$ ratio. At the LGM, we note that the $20 \%$ lower accumulation at EDC than at DF roughly corresponds to $1 / 5$ of the full magnitude of the Holocene-LGM relative accumulation variations (factor of 2 ; Fig. 5). How would this difference in SMB translate into temperature differences, assuming a constant accumulation/temperature relationship? It would correspond to a $2^{\circ} \mathrm{C}$ temperature anomaly, scaled to a $10^{\circ} \mathrm{C}$ Holocene-LGM contrast of surface temperature (Parrenin and others, 2013). This is consistent with a recent estimate of $2.5^{\circ} \mathrm{C}$ for the difference in LGM-present precipitation-weighted temperature change between the two sites, with larger amplitude estimated at EDC than at DF (Uemura and others, 2012). We therefore conclude that our inferred synchro-based SMB ratio change may be a consequence of a difference of precipitationweighted temperature change between both sites.

\subsection{Relative change of SMB and relative change of $\delta \mathrm{D}$, implications for ice-sheet modeling}

The differences between the variations of $\mathrm{SMB}_{\mathrm{EDC}} / \mathrm{SMB} \mathrm{B}_{\mathrm{DF}}$ ratio and the $\delta \mathrm{D}$ variations as well as the differences between the synchro-based and isotope-based SMB ratios, both described in Section 3, challenge the assumption of close relationships between water stable isotope and accumulation anomalies, especially during MIS5c and MIS5d. This feature has already been suggested during the early Holocene (Parrenin and others, 2007), during the last deglaciation (WAIS Divide Project Members, 2013) and from climate simulations of the last interglacial (Sime and others, 2009). Our study also indicates that this decoupling is site dependent. During the late part of the Holocene and the Eemian, our synchro-based $\mathrm{SMB}_{\mathrm{EDC}} / \mathrm{SMB}_{\mathrm{DF}}$ ratio is more constant than what is inferred from $\delta \mathrm{D}$ variations.

Clearly, the isotope-based SMB at either EDC or DF or both are associated with relative uncertainties of at least $10 \%$. Indeed, larger uncertainty ranges as possible because our synchronization method cannot detect correlated errors. This was also suggested by Fujita and others (2015) based on the same volcanic synchronization. They hypothesize that a cause of the systematic DFO2006/AICC2012 age differences in MIS 5 are associated with differences in the dating approaches, either the age-markers-based dating or the glaciological dating. They further hypothesize that major sources of the discrepancies were systematic errors in SMB estimation.

Inaccurate estimates of SMB based on water stable isotope records can cause important errors for chemical flux reconstructions and ice core chronologies but also for firn (Goujon and others, 2003) and ice-sheet (Ritz and others, 2001) modeling. For example, if the SMB evaluation at one of the two sites is wrong by as much as $20 \%$, this would lead to a $20 \%$ error in fluxes reconstructions, in events duration and in $\Delta$ age evaluation (i.e. 500-1000 a error in the ice age/gas age difference). Concerning ice-sheet modeling, we showed (Fig. 6) that our ice thickness reconstructions may be wrong by as much as $35 \mathrm{~m}$ for EDC and $60 \mathrm{~m}$ for DF (the maximum error occurring for MIS5d). Taking into account a vertical gradient of temperature of $1^{\circ} \mathrm{C}$ $(100 \mathrm{~m})^{-1}$, such ice sheet thinning would lead to an 
underestimation of the magnitude of temperature decrease 'at fixed elevation' by $\sim 0.5^{\circ} \mathrm{C}$.

\subsection{Atmospheric process, dome movement or elevation change artifact?}

In the following, we discuss three different hypotheses to explain the changes in the $\mathrm{SMB}_{\mathrm{EDC}} / \mathrm{SMB} \mathrm{B}_{\mathrm{DF}}$ ratio: regional differences in climate (at constant geometry of the ice sheet), changes of dome position affecting snow redeposition by wind, or differences in elevation changes.

Different atmospheric processes may explain the variations in the $\mathrm{SMB}_{\mathrm{EDC}} / \mathrm{SMB} \mathrm{B}_{\mathrm{DF}}$ ratio: (1) effects related to moisture sources and distillation along transport paths; (2) different glacial sea ice expansions in the Atlantic and Indian Ocean sectors (Gersonde and others, 2005), enhancing accumulation and temperature changes at EDC compared with those at DF; (3) effects associated with precipitation intermittency and/or seasonality (e.g. Suzuki and others, 2013), precipitation amounts being expected to be reduced during cold periods; (4) less frequent blocking events at EDC (Massom and others, 2004) than at DF (Hirasawa and others, 2000) during glacial periods, these warm events being responsible of a large proportion of the total annual accumulation today (Hirasawa and others, 2000); and (5) differences in sublimation, which is an important process since surface snow/vapor exchanges can alter the snowfall signal in-between snowfall events (Hoshina and others, 2014; Steen-Larsen and others, 2014).

We now explore the dome movement hypothesis. Today, we observe a spatial gradient of accumulation at Dome C (Urbini and others, 2008) and DF (Fujita and others, 2011), due to orographic precipitation or to snow redeposition by winds linked with surface curvature. Under glacial/interglacial climatic changes (e.g. migration of the grounding line), it seems natural that the ice divides locations migrate. A movement of the domes (Saito, 2002, provides information on the movement of DF during the past) could therefore create an apparent change of accumulation in the ice core records. A movement of the domes can also modify the trajectories and therefore the upstream origin of ice particles in the ice cores. Given that accumulation varies spatially, in particular due to surface topographic variations related to bedrock reliefs (Fujita and others, 2011), this second process can also create an apparent change of accumulation in the ice cores. In this case, we would not expect any constant relationship between water stable isotopes and accumulation rate, except if the dome movement is itself correlated to processes affecting the isotopic composition of water vapor and precipitation (e.g. via sea-level changes and grounding line migration).

Concerning the elevation hypothesis, it is not impossible that EDC and DF experienced different changes in elevation, since the ice flow at those two sites should not react in the same way to sea-level changes (Saito and Abe-Ouchi, 2010). On one hand, DF is relatively insensitive to sealevel changes since it is well protected by the Dronning Maud Mountains. On the other hand, EDC is very sensitive to sea-level changes since grounding lines in Wilkes Lands can advance and retreat over large distances (Mengel and Levermann, 2014). Therefore, it is expected that elevation change should be different at EDC and DF. Quantitatively, if inter-site temperature differences are driven only by ice thickness change, then using a vertical temperature gradient of $1{ }^{\circ} \mathrm{C}(100 \mathrm{~m})^{-1}$ (Krinner and Genthon, 1999), $2^{\circ} \mathrm{C}$ colder glacial conditions at EDC will translate into a 200 m relative elevation difference at the LGM between EDC and DF. This is quite large compared with the current estimates of the central East Antarctic ice sheet LGM topography, as ice-sheet simulations suggest an overall lowering of surface elevation by $\sim 120 \mathrm{~m}$ (Ritz and others, 2001), driven by the lower glacial accumulation. We however stress that these ice-sheet simulations were driven by a homogeneous scenario of accumulation changes (a hypothesis challenged by our findings), and that they have intrinsic limitations in the representation of dynamical effects associated with grounding line migration (Pattyn and others, 2012). Moreover, we remark that there are abrupt variations of the SMB ratio, for example $\sim 0.2$ during just 1 ka at 113 ka b1950, which cannot be due to elevation variations since the later are a slow integrator of surface accumulation variations and dynamical effects.

\section{CONCLUSIONS}

Our study suggests that the vertical thinning functions evaluated by ice flow models at EDC and DF are valid for the depth range covered here (the past $216 \mathrm{ka}$ ). We produce a new paleoclimatic record, the $\mathrm{SMB}_{\mathrm{EDC}} / \mathrm{SMB}_{\mathrm{DF}}$ ratio, which varies at the glacial/interglacial scale. Regional differences in climate are identified, with EDC characterized by an enhanced (+20\%) amplitude of glacial cooling and drying, compared with DF. The data show that interglacial changes in $\mathrm{SMB}_{\mathrm{EDC}} / \mathrm{SMB}_{\mathrm{DF}}$ ratio do not always scale with those of water stable isotopes, challenging classical hypotheses used for ice core chronologies and for ice-sheet modeling. The SMB ratio reduces strongly in MIS 5d and 5c, 20\% lower than what would be deduced from the isotopes. Moreover, the SMB ratio is almost constant during the late parts of the current and last interglacial periods, in contradiction with contrasting isotopic trends at EDC and DF. Our reconstructions of $\mathrm{SMB}$ at EDC and DF might be improved in the future by using new aerosols records with nearly constant fluxes above Antarctica, for example, beryllium-10 (Cauquoin and others, 2015). Changes in the SMB $\mathrm{EDC}_{\mathrm{E}}$ $\mathrm{SMB}_{\mathrm{DF}}$ ratio may be due to regional climate differences at the two sites, to an artifact of dome movement influencing snow redistribution by wind, or to a different change of elevation at the two sites. Further studies are necessary to discriminate between these three hypotheses. In particular, new simulations of Antarctic ice sheet evolution using a new generation of ice-sheet models with a realistic representation of grounding line migrations (e.g. Pollard and DeConto, 2012) will allow exploration of the movements and elevation variations of the domes. There is also a need for more accurate atmospheric models able to reproduce the measured present or past spatial pattern of accumulation. Expanding this approach towards other sites will also give more regional information on the past SMB pattern. The inferred regional differences in SMB variations should also be taken into account in glacial-interglacial Antarctic ice sheet modeling.

\section{AUTHOR CONTRIBUTION}

The writing of this paper was led by the two first authors: F. Parrenin and S. Fujita. They contributed equally and share the responsibilities for this paper. They carried out the synchronization work, led discussions and oversaw the writing of this paper. E. Wolff and M. Severi provided 
the EDC electrical profile data and EDC sulfate data, respectively. S. Fujita and $\mathrm{H}$. Motoyama provided the entire electrical profile data of the DF core. All authors joined in the scientific discussions.

\section{ACKNOWLEDGEMENTS}

We thank Gerhard Krinner, Catherine Ritz, Kazue Suzuki, Jean Jouzel, Michiel Van Den Broeke and the GLACE team at LGGE for helpful discussions. We wish to also thank all participants to the field seasons at Dome C. The main logistic support was provided by IPEV and PNRA at Dome C. This work is a contribution to the European Project for Ice Coring in Antarctica (EPICA), a joint European Science Foundation/European Commission scientific program, funded by the EU and by national contributions from Belgium, Denmark, France, Germany, Italy, The Netherlands, Norway, Sweden, Switzerland and the UK. This is EPICA publication nb 305. This study was supported by a grant from the CNRS/INSU/LEFE program ('IceChrono' proposal). We also thank all the Dome Fuji Deep Ice Core Project members who contributed to obtaining the ice core samples, either through logistics, drilling or core processing. The main logistics support was provided by the Japanese Antarctic Research Expedition (JARE), managed by the Ministry of Education, Culture, Sports, Science and Technology (MEXT). This study was supported in part by a Grant-in-Aid for Scientific Research (A) (20241007) and a Grant-in-Aid for Young Scientists (S) (21671001) from the Japan Society for the Promotion of Science (JSPS). The manuscript was prepared with the support of National Institute of Polar Research (NIPR) publication subsidy.

\section{REFERENCES}

Aristidi E and 11 others (2005) An analysis of temperatures and wind speeds above Dome C, Antarctica. Astron. Astrophys. 430(2), 739-746 (doi: 10.1051/0004-6361:20041876)

Bazin L and 21 others (2013) An optimized multi-proxy, multi-site Antarctic ice and gas orbital chronology (AICC2012): 120-800 ka. Clim. Past 9(4), 1715-1731 (doi: 10.5194/cp-9-1715-2013)

Bengtsson L, Koumoutsaris S and Hodges K (2011) Large-scale surface mass balance of ice sheets from a comprehensive atmospheric model. Surv. Geophys. 32(4), 459-474 (doi: 10.1007/ s10712-011-9120-8)

Bintanja R, de Wal RSW and Oerlemans J (2005) Modelled atmospheric temperatures and global sea levels over the past million years. Nature 437, 125-128 (doi: 10.1038/nature03975)

Cauquoin A and 9 others (2015) Comparing past accumulation rate reconstructions in East Antarctic ice cores using 10Be, water isotopes and CMIP5-PMIP3 models. Clim. Past 11(3), 355-367 (doi: 10.5194/cp-11-355-2015)

Cavitte MG and 7 others (2016) Deep radiostratigraphy of the East Antarctic plateau: connecting the Dome $\mathrm{C}$ and Vostok ice core sites. J. Glaciol. 62(232), 323-334 (doi: 10.1017/jog.2016.11)

Church JA and 13 others (2013) Sea level change. In Stocker TF, Qin D, Plattner G-K, Tignor M, Allen SK, Boschung J, Nauels A, Xia Y, Bex V and Midgley PM eds. Climate change 2013: the physical science basis. contribution of working group I to the fifth assessment report of the intergovernmental panel on climate change. Cambridge, United Kingdom and New York, NY, USA. http://ipcc.ch/report/ar5/wg1/

Dansgaard W (1964) Stable isotopes in precipitation. Tellus 16, 436468 (doi: 10.1111/j.2153-3490.1964.tb00181.x)

Durand G and 8 others (2007) Change in ice rheology during climate variations - implications for ice flow modelling and dating of the EPICA Dome C core. Clim. Past 3, 155-167 (doi: 10.5194/cp-3-155-2007)

Durand G and 7 others (2009) Evolution of the texture along the EPICA Dome C ice core. Low Temp. Sci. 68(Supplement), 91-105

Ekaykin A (2003) Régime météorologique de l'Antarctique central et son rôle dans la composition isotopique de la neige. Faculté de géographie de Saint Pétersbourg. http://tel.archives-ouvertes.fr/ tel-00701466

EPICA community members (2004) 8 glacial cycles from an Antarctic ice core. Nature 429, 623-628 (doi: 10.1038/ nature02599)

Frezzotti M and 13 others (2004) New estimations of precipitation and surface sublimation in East Antarctica from snow accumulation measurements. Clim. Dyn. 23(7-8), 803-813 (doi: 10.1007/ s00382-004-0462-5)

Frezzotti M, Scarchilli C, Becagli S, Proposito M and Urbini S (2013) A synthesis of the Antarctic surface mass balance during the last 800 yr. Cryosphere 7(1), 303-319 (doi: 10.5194/tc-7-303-2013)

Fujita K and Abe O (2006) Stable isotopes in daily precipitation at Dome Fuji, East Antarctica. Geophys. Res. Lett. 33(18), L18503 (doi: 10.1029/2006GL026936)

Fujita S and 6 others (1999) Nature of radio echo layering in the Antarctic Ice Sheet detected by a two-frequency experiment. J. Geophys. Res. Solid Earth 104(B6), 13013-13024 (doi: 10.1029/1999JB900034)

Fujita S and 9 others and others (2011) Spatial and temporal variability of snow accumulation rate on the East Antarctic ice divide between Dome Fuji and EPICA DML. Cryosphere 5, 10571081 (doi: 10.5194/tc-5-1057-2011)

Fujita $S$ and 7 others (2012) Radar diagnosis of the subglacial conditions in Dronning Maud Land, East Antarctica. Cryosphere 6(5), 1203-1219 (doi: 10.5194/tc-6-1203-2012)

Fujita S, Parrenin F, Severi M, Motoyama H and Wolff EW (2015) Volcanic synchronization of Dome Fuji and Dome C Antarctic deep ice cores over the past 216 kyr. Clim. Past 11(10), 13951416 (doi: 10.5194/cp-11-1395-2015)

Gallée H and 5 others (2012) Transport of snow by the wind: a comparison between observations in Adélie Land, Antarctica, and simulations made with the regional climate model MAR. Bound. Layer Meteorol. 146(1), 133-147 (doi: 10.1007/ s10546-012-9764-z)

Gersonde R, Crosta X, Abelmann A and Armand L (2005) Sea-surface temperature and sea ice distribution of the Southern Ocean at the EPILOG Last Glacial Maximum-a circum-Antarctic view based on siliceous microfossil records. Quat. Sci. Rev. 24(7-9), 869896 (doi: 10.1016/j.quascirev.2004.07.015)

Goujon C, Barnola J-M and Ritz C (2003) Modeling the densification of polar firn including heat diffusion: application to close-off characteristics and gas isotopic fractionation for Antarctica and Greenland sites. J. Geophys. Res. 108 (D24), ACL10/1-10 (doi: 10.1029/2002JD003319)

Hirasawa N, Nakamura H and Yamanouchi T (2000) Abrupt changes in meteorological conditions observed at an inland Antarctic Station in association with wintertime blocking. Geophys. Res. Lett. 27(13), 1911-1914 (doi: 10.1029/1999GL011039)

Hoshina $Y$ and 8 others (2014) Effect of accumulation rate on water stable isotopes of near-surface snow in inland Antarctica. J. Geophys. Res. Atmos. 119(1), 2013JD020771 (doi: 10.1002/ 2013JD020771)

lizuka $Y$ and 6 others (2012) Sulphate-climate coupling over the past 300000 a in inland Antarctica. Nature 490(7418), 81-84 (doi: 10.1038/nature11359)

Jouzel J and Merlivat L (1984) Deuterium and oxygen 18 in precipitation: modeling of the isotopic effects during snow formation. J. Geophys. Res. Atmos. 89(D7), 11749-11757 (doi: 10.1029/ JD089iD07p11749)

Jouzel J and 6 others (1987) Vostok ice core: a continuous isotope temperature record over the last climatic cycle (160000 a). Nature 329(6138), 403-408 (doi: 10.1038/329403a0) 
Jouzel J and 6 others (2003) Magnitude of isotope/temperature scaling for interpretation of central Antarctic ice cores. J. Geophys. Res. Atmos. 108(D12), 4361 (doi: 10.1029/2002JD002677)

Jouzel J and 31 others (2007) Orbital and millennial Antarctic climate variability over the past 800000 a. Science 317(5839), 793-796 (doi: 10.1126/science.1141038)

Kameda T and 9 others (1997) Meteorological observations along a traverse route from coast to Dome Fuji Station, Antarctica, recorded by Automatic Weather Stations in 1995. Proc. of the NIPR Symp. on Polar Meteorology and Glaciology. 35-50

Kameda T, Motoyama H, Fujita S and Takahashi S (2008) Temporal and spatial variability of surface mass balance at Dome Fuji, East Antarctica, by the stake method from 1995 to 2006. J. Glaciol. 54 (184), 107-116 (doi: 10.3189/002214308784409062)

Kawamura K and 11 others (2007) Northern hemisphere forcing of climatic cycles over the past 360000 a implied by absolute dating of Antarctic ice cores. Nature 448, 912-917 (doi: 10.1038/nature06015)

King JC, Argentini SA and Anderson PS (2006) Contrasts between the summertime surface energy balance and boundary layer structure at Dome C and Halley stations, Antarctica. J. Geophys. Res. Atmos. 111(D2), D02105 (doi: 10.1029/2005JD006130)

Krinner G and Genthon C (1999) Altitude dependence of the ice sheet surface climate. Geophys. Res. Lett. 26(15), 2227-2230 (doi: 10.1029/1999GL900536)

Lisiecki LE and Raymo ME (2005) A plio-pleistocene stack of 57 globally distributed benthic $\delta^{18} \mathrm{O}$ records. Paleoceanography $\mathbf{2 0}(1)$, PA1003 (doi: 10.1029/2004PA001071)

Lliboutry L (1979) A critical review of analytical approximate solutions for steady state velocities and temperature in cold ice sheets. Z. Gletscherkd. Glacialgeol. 15(2), 135-148

Massom RA and 6 others (2004) Precipitation over the Interior East Antarctic ice sheet related to midlatitude blocking-high activity. J. Clim. 17(10), 1914-1928 (doi: 10.1175/1520-0442(2004) 017<1914:POTIEA > 2.0.CO;2)

Masson-Delmotte $V$ and 35 others (2008) A review of Antarctic surface snow isotopic composition: observations, atmospheric circulation, and Isotopic modeling. J. Clim. 21(13), 3359-3387 (doi: 10.1175/2007JCLI2139.1)

Masson-Delmotte $\mathrm{V}$ and 18 others (2011) A comparison of the present and last interglacial periods in six Antarctic ice cores. Clim. Past 7(2), 397-423 (doi: 10.5194/cp-7-397-2011)

Mengel M and Levermann A (2014) Ice plug prevents irreversible discharge from East Antarctica. Nat. Clim. Change 4(6), 451455 (doi: 10.1038/nclimate2226)

Motoyama H (2007) The Second Deep Ice Coring Project at Dome Fuji, Antarctica. Sci. Drill. 5, 41-43 (doi: 10.2204/iodp. sd.5.05.2007)

Motoyama H, Hirasawa N, Satow K and Watanabe O (2005) Seasonal variations in oxygen isotope ratios of daily collected precipitation and wind drift samples and in the final snow cover at Dome Fuji Station, Antarctica. J. Geophys. Res. Atmos. 110(D11), D11106 (doi: 10.1029/2004JD004953)

Motoyama $\mathrm{H}$ and others (2007) A New 3035.22 m deep ice core at dome Fuji, Antarctica and reconstruction of global climate and environmental change over past $720 \mathrm{kyr}$. AGU Fall Meeting Abstracts. $\mathbf{7 6}$

Parish TR and Bromwich DH (1987) The surface windfield over the Antarctic ice sheets. Nature 328(6125), 51-54 (doi: 10.1038/ 328051a0)

Parrenin F, Rémy F, Ritz C, Siegert M and Jouzel J (2004) New modelling of the Vostok ice flow line and implication for the glaciological chronology of the Vostok ice core. J. Geophys. Res. 109, D20102 (doi: 10.1029/2004JD004561)

Parrenin F and 15 others (2007) 1-D-ice flow modelling at EPICA Dome C and Dome Fuji, East Antarctica. Clim. Past 3(2), 243259 (doi: 10.5194/cp-3-243-2007)

Parrenin F and 9 others (2013) Synchronous change of Atmospheric $\mathrm{CO}_{2}$ and Antarctic temperature during the last deglacial warming. Science 339(6123), 1060-1063 (doi: 10.1126/ science.1226368)

Pattyn F and 18 others (2012) Results of the Marine Ice Sheet Model Intercomparison Project, MISMIP. Cryosphere 6(3), 573-588 (doi: 10.5194/tc-6-573-2012)

Pollard D and DeConto RM (2012) Description of a hybrid ice sheetshelf model, and application to Antarctica. Geosci. Model Dev. 5 (5), 1273-1295 (doi: 10.5194/gmd-5-1273-2012)

Raymond CF (1983) Deformation in the vicinity of ice divides. J. Glaciol. 29(103), 357-373

Reijmer CH, van den Broeke MR and Scheele MP (2002) Air parcel trajectories and snowfall related to five deep drilling locations in Antarctica based on the ERA-15 Dataset. J. Clim. 15(14), 19571968 (doi: 10.1175/1520-0442(2002)015<1957:APTASR > 2.0. $\mathrm{CO} ; 2)$

Rignot E, Mouginot J, Morlighem M, Seroussi H and Scheuchl B (2014) Widespread, rapid grounding line retreat of Pine Island, Thwaites, Smith, and Kohler glaciers, West Antarctica, from 1992 to 2011. Geophys. Res. Lett. 41(10), 3502-3509 (doi: 10.1002/2014GL060140)

Ritter F and 9 others (2016) Isotopic exchange on the diurnal scale between near-surface snow and lower atmospheric water vapor at Kohnen station, East Antarctica. Cryosph. Discuss., 1-35 (doi: 10.5194/tc-2016-4)

Ritz C, Rommelaere V and Dumas C (2001) Modeling the evolution of Antarctic ice sheet over the last 420000 a: implications for altitude changes in the Vostok region. J. Geophys. Res. Atmos. 106(D23), 31943-31964 (doi: 10.1029/2001JD900232)

Saito F (2002) Development of a three dimensional ice sheet model for numerical studies of Antarctic and Greenland ice sheet. University of Tokyo, Department of Earth and Planetary Science, Tokyo, Japan

Saito F and Abe-Ouchi A (2010) Modelled response of the volume and thickness of the Antarctic ice sheet to the advance of the grounded area. Ann. Glaciol. 51(55), 41-48 (doi: 10.3189/ 172756410791392808)

Scarchilli C, Frezzotti M and Ruti PM (2011) Snow precipitation at four ice core sites in East Antarctica: provenance, seasonality and blocking factors. Clim. Dyn. 37(9-10), 2107-2125 (doi: 10.1007/s00382-010-0946-4)

Siegert MJ, Hodgkins R and Dowdeswell JA (1998) A chronology for the Dome $\mathrm{C}$ deep ice-core site through radio-echo layer Correlation with the Vostok Ice Core, Antarctica. Geophys. Res. Lett. 25(7), 1019-1022 (doi: 10.1029/98GL00718)

Sime LC, Wolff EW, Oliver KIC and Tindall JC (2009) Evidence for warmer interglacials in East Antarctic ice cores. Nature $\mathbf{4 6 2}$ (7271), 342-345 (doi: 10.1038/nature08564)

Sodemann H and Stohl A (2009) Asymmetries in the moisture origin of Antarctic precipitation. Geophys. Res. Lett. 36(22), L22803 (doi: 10.1029/2009GL040242)

Steen-Larsen HC and 18 others (2014) What controls the isotopic composition of Greenland surface snow? Clim. Past 10(1), 377-392 (doi: 10.5194/cp-10-377-2014)

Stenni B and 7 others (2001) An oceanic cold reversal during the last deglaciation. Science 293(5537), 2074-2077 (doi: 10.1126/ science.1059702)

Stenni B and 14 others (2010) The deuterium excess records of EPICA Dome C and Dronning Maud Land ice cores (East Antarctica). Quat. Sci. Rev. 29(1-2), 146-159 (doi: 10.1016/j. quascirev.2009.10.009)

Suzuki K, Yamanouchi T and Motoyama H (2008) Moisture transport to Syowa and Dome Fuji stations in Antarctica. J. Geophys. Res. Atmos. 113(D24), D24114 (doi: 10.1029/2008JD009794)

Suzuki K, Yamanouchi T, Kawamura K and Motoyama H (2013) The spatial and seasonal distributions of air-transport origins to the Antarctic based on 5-day backward trajectory analysis. Polar Sci. 7(3-4), 205-213 (doi: 10.1016/j.polar.2013.08.001)

Tabacco IE, Passerini A, Corbelli F and Gorman M (1998) Determination of the surface and bed topography at Dome C, East Antarctica. J. Glaciol. 44, 185-191 
Takahashi S, Ageta Y, Fujii Y and Vvataabe O (1994) Surface mass balance in east Dronning Maud Land, Antarctica, observed by Japanese Antarctic research expeditions. Ann. Glaciol. 20(1), 242-248

Takahashi S, Kameda T, Enomoto H, Motoyama $\mathrm{H}$ and Watanabe $\mathrm{O}$ (2004) Automatic Weather Station (AWS) data collected by the 33rd to 42nd Japanese Antarctic Research Expeditions during 1993-2001. JARE Data Rep. Meteorol. 36, 1-416

Uemura R and 5 others (2012) Ranges of moisture-source temperature estimated from Antarctic ice cores stable isotope records over glacial-interglacial cycles. Clim. Past 8(3), 1109-1125 (doi: 10.5194/cp-8-1109-2012)

Urbini S and 6 others (2008) Historical behaviour of Dome C and Talos Dome (East Antarctica) as investigated by snow accumulation and ice velocity measurements. Glob. Planet. Change 60(3-4), 576-588 (doi: 10.1016/j.gloplacha.2007.08.002)
Veres D and 15 others (2013) The Antarctic ice core chronology (AICC2012): an optimized multi-parameter and multi-site dating approach for the last 120 thousand years. Clim. Past 9 (4), 1733-1748 (doi: 10.5194/cp-9-1733-2013)

WAIS Divide Project Members (2013) Onset of deglacial warming in West Antarctica driven by local orbital forcing. Nature 500 (7463), 440-444 (doi: 10.1038/nature12376)

Watanabe $\mathrm{O}$ and 5 others (2003a) Homogeneous climate variability across East Antarctica over the past three glacial cycles. Nature 422(6931), 509-512 (doi: 10.1038/nature01525)

Watanabe O and 11 others (2003b) General tendencies of stable isotopes and major chemical constituents of the Dome Fuji deep ice core. Mem. Natl. Inst. Polar Res. Spec. 57, 1-24

Wolff EW and 27 others (2006) Southern Ocean sea-ice extent, productivity and iron flux over the past eight glacial cycles. Nature 440(7083), 491-496 (doi: 10.1038/nature04614)

MS received 3 March 2016 and accepted in revised form 9 June 2016; first published online 1 August 2016 